\title{
Evaluation of Rutting in Conventional and Rubberized Asphalt Mixes Using Numerical Modeling Under Repeated Loads
}

\author{
Dhuha Ameir Saad \\ Department of Civil Engineering \\ College of Engineering \\ University of Baghdad \\ Baghdad, Iraq \\ d.saad1901m@coeng.uobaghdad.edu.iq
}

\author{
Hayder A. Al-Baghdadi \\ Department of Civil Engineering \\ College of Engineering \\ University of Baghdad \\ Baghdad, Iraq \\ baghdadi.hayder@coeng.uobaghdad.edu.iq
}

\begin{abstract}
This research aimed to predict the permanent deformation (rutting) in conventional and rubberized asphalt mixes under repeated load conditions using the Finite Element Method (FEM). A three-dimensional (3D) model was developed to simulate the Wheel Track Testing (WTT) loading. The study was conducted using the Abaqus/Standard finite element software. The pavement slab was simulated using a nonlinear creep (time-hardening) model at $40^{\circ} \mathrm{C}$. The responses of the viscoplastic model under the influence of the trapezoidal amplitude of moving wheel loadings were determined for different speeds and numbers of cycles. The results indicated that a wheel speed increase from $0.5 \mathrm{Km} / \mathrm{h}$ to $1.0 \mathrm{Km} / \mathrm{h}$ decreased the rut depth by about $22 \%$ and $24 \%$ in conventional and rubberized asphalt mixes, respectively. Moreover, increasing the number of cycles from $7,500(15,000$ passes) to 15,000 (30,000 passes) under constant speed increased the rut depth by about $25 \%$ and $30 \%$ in conventional and rubberized asphalt mixes, respectively. Furthermore, the addition of Crumb Rubber (CR) to the asphalt reduced its rut depth by $55 \%$ compared to conventional asphalt.
\end{abstract}

Keywords-rutting; finite element method; rubberized asphalt; repeated load; creep

\section{INTRODUCTION}

Rutting distress is one of the most common types of failure in flexible pavements. It is generated by accumulated permanent deformations in the wheel path as a result of repeated axle loads [1]. The rutting depth is an important factors to assess a pavement's condition [2]. Pavements are complex systems that include several variables that affect their performance [3]. The behavior of non-linear asphalt mixtures is divided into two types: viscoelastic and viscoplastic, which are associated with recoverable and non-recoverable deformations, respectively $[4,5]$. Temperature is one of the most critical factors affecting the resistance of asphalt pavement to rutting. Temperature variations allow the asphalt pavement to expand and contract, altering the asphalt mixture's characteristics and resulting in pavement deformation [6]. Moreover, the increasing number of loading cycles affects the asphalt paving, as the rutting develops gradually and usually appears in the wheel tracks as a longitudinal drop with small side upheavals
[7]. Lower vehicle speed results in a longer load period and lower frequency, having a greater effect on permanent deformation compared to higher speeds for the same number of passes [8]. Hot asphalt mixture at low temperatures and high loading speed are considered as a liquid plastic thermoplastic, while high temperatures and slow loading appear as a viscous liquid and elastic solid. This classic duality necessitates the improvement of the asphalt binder's performance to reduce cracking stresses at low temperatures and plastic deformations at high temperatures.

One method to achieve the specified pavement performance standards is to use a polymer-modified asphalt binder [9]. It is therefore imperative to enhance the properties of the conventional asphalt content, as well as the advancement of successful asphalt mix design technology $[10,11]$. Overall, Crumb Rubber Modifier (CRM) additions appear to improve the maximal initial strength of conventional asphalt [12]. CRM is a powder produced by crushing and grinding vehicle waste tires [13]. To anticipate permanent deformation, a variety of analytical methods are available such as multilayer elastic theory, Finite Difference Method (FDM), and Finite Element Method (FEM) [14]. There are several advantages of using finite element analysis. These advantages include the modeling capabilities on the model geometry designs that are irregularly shaped or complex, various loading options, representation of an unlimited number of materials, unlimited boundary conditions, and finally a study of large deformations with nonlinear behavior of viscoplastic response [15]. FEM depends on inputs obtained from the experimental data of bituminous materials. This study used the parameters adopted in [16]. The main objective of the current research was to study the effect of repeated wheel loading under the influence of different speeds and the number of loading cycles. To investigate the impact of the assumptions on rutting predictions, a Wheel Tracking Test (WTT) was simulated in a 3D finite element model generated from rubberized and conventional asphalt mixtures. The Abaqus software was utilized, as it includes a creep power-law model that simulates the viscoplastic behavior of the asphalt layer. 


\section{METHOD}

The WTT was simulated as an illustration of how rutting forecasts are affected by repeated wheel loading assumptions at different speeds and numbers of passes. A three-dimensional FEM model was constructed using flexible pavements made from conventional and rubberized asphalt mixtures. The asphalt layer was modeled as a viscoplastic substance using the creep power-law model (time-hardening) of the Abaqus software.

\section{CREEP POWER-LAW}

A constitutive model of viscoplastic deformation for flexible pavements developed in the Abaqus software [18] was adopted, which, despite its simplicity, is used to solve complex problems [17]. The model is given by:

$$
\varepsilon_{\mathrm{v}}=A \sigma^{\mathrm{n}} t^{\mathrm{m}}
$$

where $\varepsilon_{v}$ is the creep strain rate, $\sigma$ is the equivalent stress, $t$ is the time of loading, and $A, n$, and $m$ are the model's parameters. The parameters were obtained from laboratory tests by using the dynamic creep test [16] listed in Table I. An important assumption in this analysis is the use of the creep power-law model to depict the nonlinear behavior of the asphalt concrete mixture. The hardening time assumption available in the Abaqus library was used. Creep is the time-dependent behavior of a solid material to deform under constant stress less than the yield stress of the material. All non-recoverable components must be included during asphalt mix permanent deformation analysis, particularly viscous deformation. There are three stages to typical nonlinear creep behavior: primary, secondary, and tertiary, as shown in Figure 1.

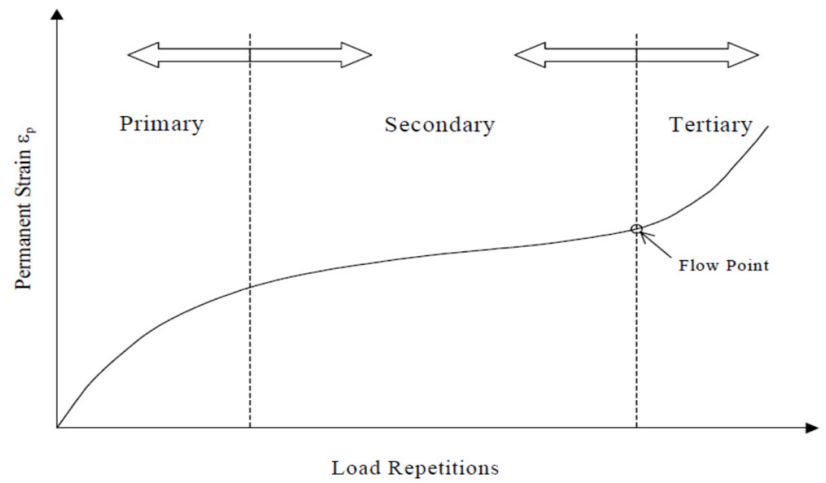

Fig. 1. Te three stages of plastic strain in repeated load creep testing.

TABLE I. LAW PARAMETERS OF THE CREEP MODEL

\begin{tabular}{|c|c|c|c|c|}
\hline Mix type & Temperature $\left({ }^{\circ} \mathbf{C}\right)$ & $\mathbf{A}(\mathbf{e}-5)$ & $\mathbf{n}$ & $\mathbf{m}$ \\
\hline $\begin{array}{c}\text { Rubberized } \\
\text { asphalt }\end{array}$ & 40 & 4.2 & 1.5 & -0.609 \\
\hline $\begin{array}{c}\text { Conventional } \\
\text { asphalt }\end{array}$ & 40 & 7.3 & 1.5 & -0.570 \\
\hline
\end{tabular}

\section{FEM SIMULATION}

This section describes the 3D finite element simulation of asphalt slab in a WTT, the employed wheel loading assumptions, and a synopsis of an analysis technique to determine the material properties associated with the presented constitutive model. FEM has been proven to be suitable for analyzing the complex nonlinear behavior of composite pavement materials and has been effectively applied to flexible pavement performance analysis [19]. Numerical simulation in pavement engineering is an efficient and effective way to verify the pavement's response and performance under moving vehicle loads. It is an easy, inexpensive, and time-reducing method, in addition to the versatility and flexibility required for WTT simulation [18]. Abaqus was adopted to simulate the paving structure, as it is a powerful FEM software that can easily solve complicated problems by using nonlinear analysis for the realization of the basic concept. The software includes a library with many finite elements and different behavior models of materials. Abaqus can automatically select reasonable increments and logical defaults.

\section{A. Geometry, Boundary Conditions, and Meshing}

Defining the physical model is the first step of FEM. Figure 1 presents the geometry of the studied WTT. Its dimensions were $300 \times 300 \times 50 \mathrm{~mm}$ in length, width, and depth respectively as shown in Figure 2. These dimensions were chosen to correspond with the WTT specimens [16].

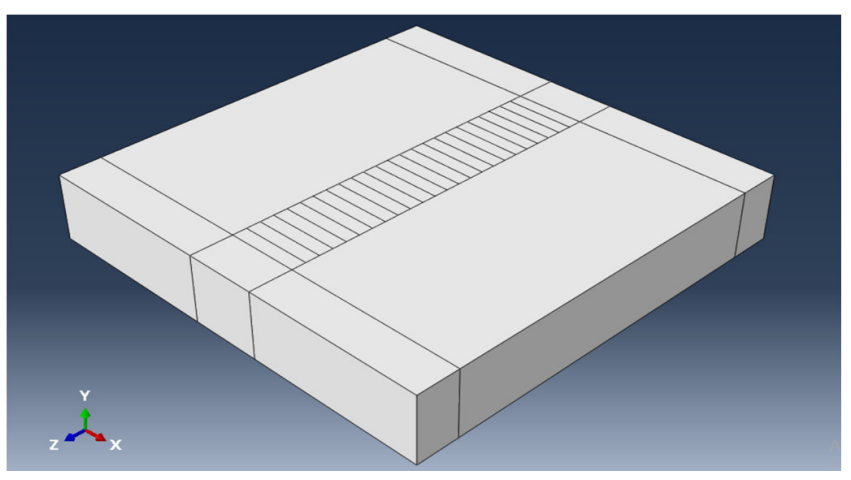

Fig. 2. Three-dimensional slab modeling.

The model's boundary conditions were modeled by specimen circumstances in WTT. Boundary conditions have a major influence on expected responses since they have a strong influence on the reaction of the form. The bottom surface of the bituminous wheel tracking test slab was assumed to be fixed and restrained in all directions to have a completely fixed end. The nodes at the bottom were unable to move horizontally or vertically, simulating the experimental conditions, while the upper surface of the sample was free to move. The side edges were constrained in the horizontal but not in the vertical direction, as shown in Figure 3.

The body was divided into 960 small, discrete Finite Elements (FEs), which were all resolved at the same time for all simulations. These FEs were connected to 1581 common shared nodes. The mesh was formed by combining nodes and elements, as shown in Figure 4. The size of the element mesh has a significant impact on numerical accuracy, while the fine mesh size requires a longer time for model analysis. 


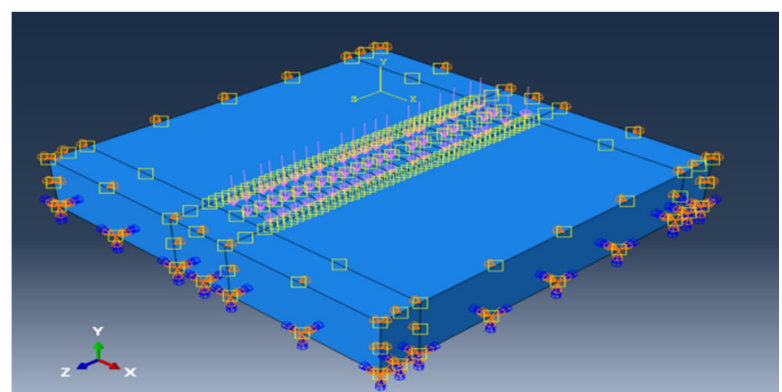

Fig. 3. Boundary conditions, temperature distribution, and loading along the wheel path.

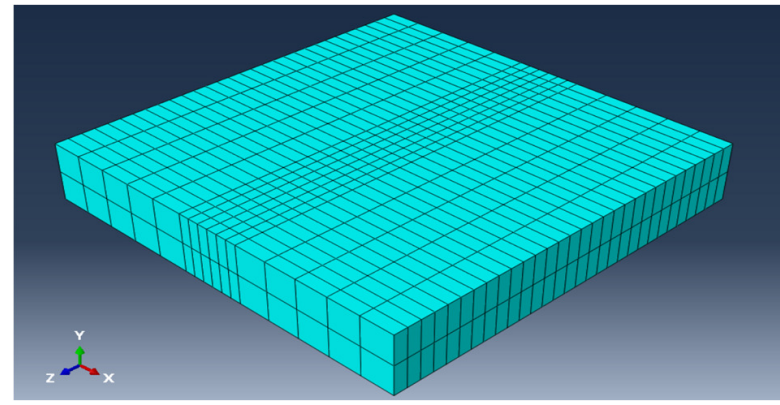

Fig. 4. Mesh of 3D finite element model.

\section{B. Employed Material Parameters}

The viscoplastic permanent deformation properties of the flexible pavement materials are usually determined using the Dynamic Creep Test. Abaqus is efficient in analyzing complex time rate-dependent and viscoplastic problems. The timehardening version of the power-law creep model is most suitable when the stress state remains essentially constant. Temperature is an important factor affecting the corrosion resistance of all mixtures. All materials' model parameters used in the simulation, the elastic modulus, and Poisson's ratio were collected from laboratory results [16]. An elastic modulus of $3,800 \mathrm{MPa}$ and a Poisson's ratio of 0.35 were also obtained from laboratory results.

\section{Characterization of Moving Wheel Load Amplitude}

A $150 \mathrm{kPa}$ uniform vertical tire pressure was adopted in the simulation of a moving load. The moving load was applied along the test path with a length of $230 \pm 10 \mathrm{~mm}$. Under the influence of a $40^{\circ} \mathrm{C}$ temperature applied to the entire model, the contact pressure will be equal to the tire pressure when the stiffness effect of the tire wall is neglected, according to the National Cooperative Highway Research Program (NCHRP), where the load was simplified and assumed as a rectangular area and distributed evenly on the loading footprint of $50 \mathrm{~mm}$ and $30 \mathrm{~mm}$ in length and width respectively [20]. To simulate the gradual loading of the test wheel back and forth, the loading path was divided into 8 regions, depending on the length of the wheel path and the tire footprint, and then each region was having one-third of the wheel loads. This load was applied repeatedly overlapping to the wheel path. The repeated load was applied with trapezoidal amplitude and the loading time for one pass at $0.5 \mathrm{Km} / \mathrm{h}$ was $1.728 \mathrm{~s}$, as shown in Figure 5.

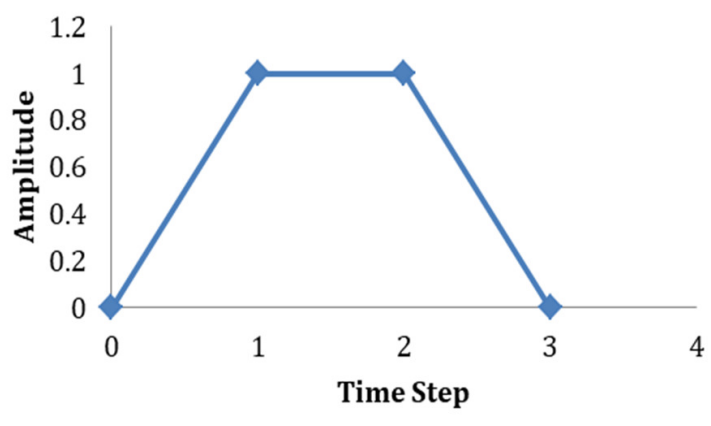

Fig. 5. Repeated loading amplitude of one pass.

\section{SEnSitivity ANaLysis}

Sensitivity analysis was carried out to study how the wheel speed and the number of loading cycles affect the reaction of flexible pavements, depending on the mixture type.

\section{A. Wheel Speed}

Hot Mix Asphalt (HMA) is a time-dependent material. As a result, wheel speed, which is proportional to loading duration, is likely to affect the reactivity of HMA mixes. When it increases, loading time and rut depth decreases, and vice versa. This explains the rutting in the pavement in crossroads and other places where vehicles move slowly. Rut depths predicted for 10,000 loading cycles $(20,000$ passes $)$ at 0.5 and $1.0 \mathrm{Km} / \mathrm{h}$ wheel speeds are shown in Figures 6 and 7 for rubberized and conventional asphalt pavements, respectively. The decrease in crack depth when increasing speed from $0.5 \mathrm{Km} / \mathrm{h}$ to $1.0 \mathrm{Km} / \mathrm{h}$ is about $22 \%$ and $24 \%$ in the conventional and rubberized mixture, respectively, as shown in Figure 8.

(a)

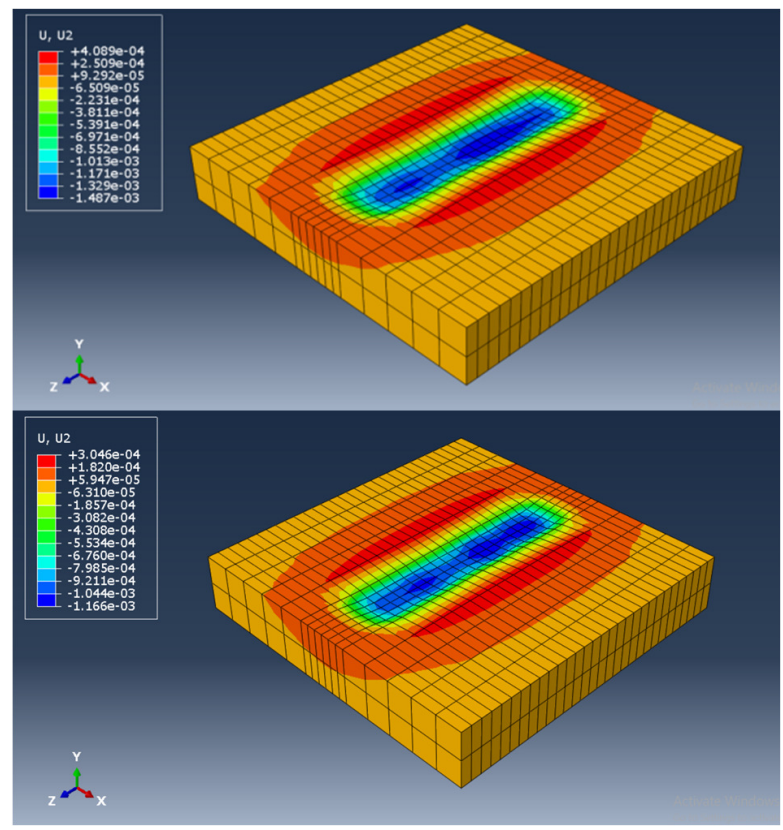

Fig. 6. Predicting rutting under repeated loading for rubberized asphalt pavement at 20,000 passes at different speeds, (a) $0.5 \mathrm{Km} / \mathrm{h}$, (b) $1.0 \mathrm{Km} / \mathrm{h}$. 
(a)

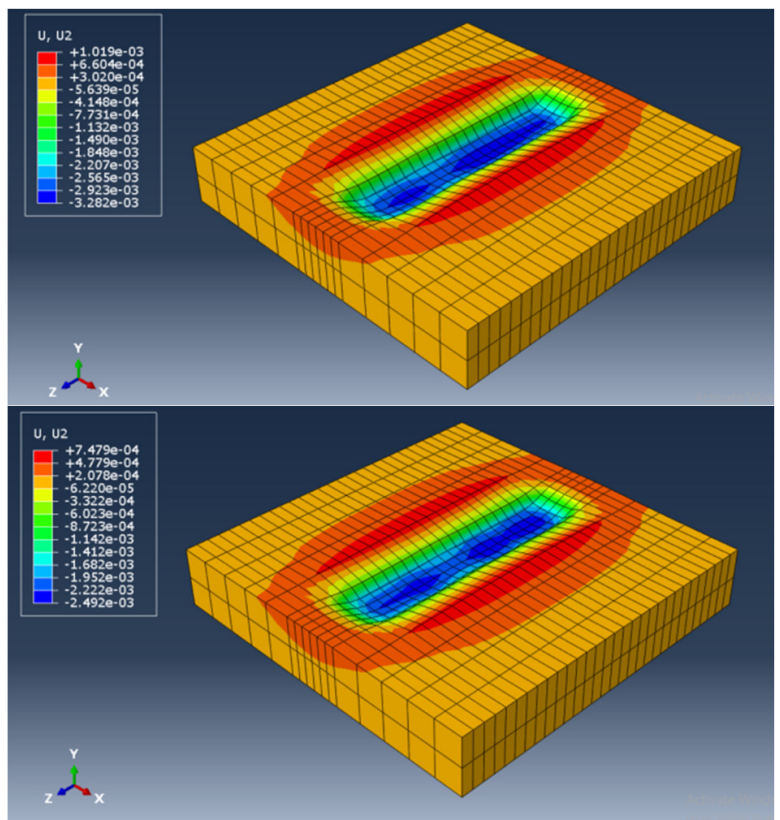

Fig. 7. Predicting rutting under repeated loading for conventional asphalt pavement at 20,000 passes at different speeds, (a) $0.5 \mathrm{Km} / \mathrm{h}$, (b) $1.0 \mathrm{Km} / \mathrm{h}$.

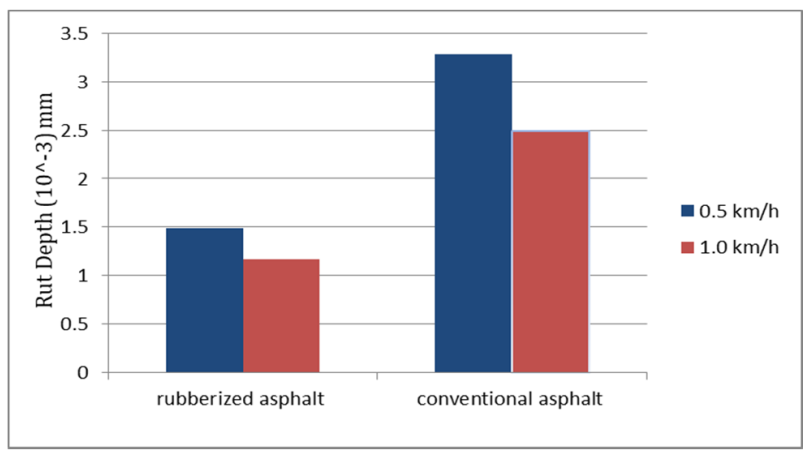

Fig. 8. Comparison of rutting under repeated load for conventional and rubberized asphalt pavements at 20,000 passes with different speeds.

\section{B. Number of Cycles}

The major cause of rutting in wheel paths can be correlated to wheel load repetitions. The accumulation of permanent deformation, which rises with the number of loading cycles, is the basic mechanism of rutting. Larger loading stress causes more rutting at steady temperatures and speeds. Figure 9 indicates that increasing the number of passes increases the rutting values of asphalt samples. On the other hand, rubber asphalt reduces rutting values compared to ordinary samples.

\section{CONCLUSION}

This paper presented a study on the permanent deformation of conventional and rubberized asphalt mixes based on repeated loads. A three-dimensional viscoplastic model was developed to simulate the WTT. The creep behavior of such mixtures was investigated based on creep power-law parameters. The following conclusions were obtained: (a)
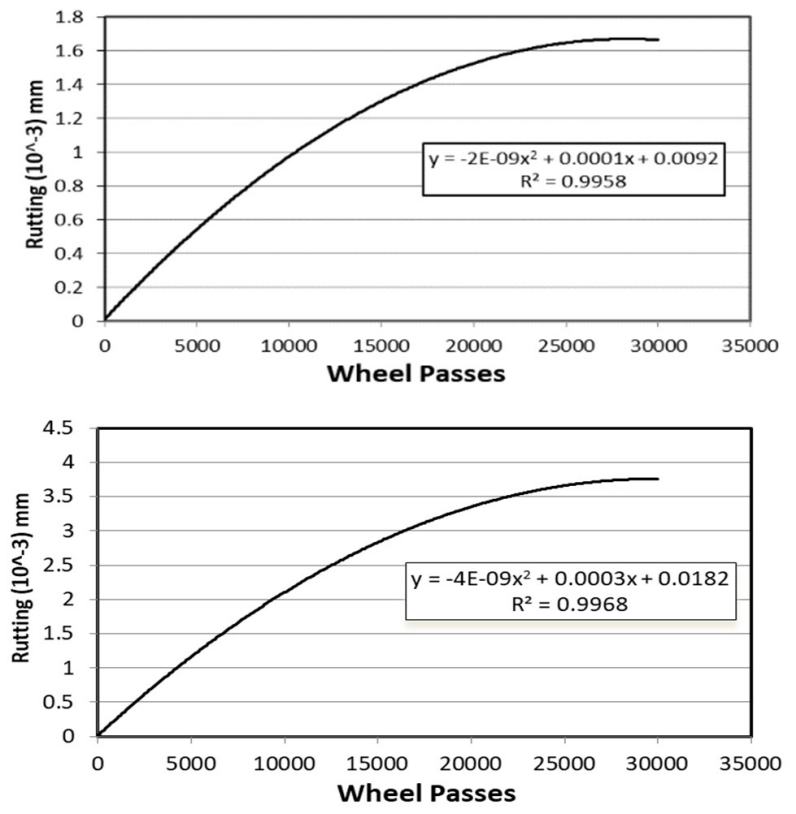

Fig. 9. Rutting with different numbers of passes in the model of WTT, (a) rubberized asphalt, (b) conventional asphalt.

- Rubber crumbs improve the rutting performance of asphalt specimens, as they reduce the rut depth of the rubberized asphalt by $55 \%$.

- The results showed that the proposed numerical models portrait satisfactorily the rut behavior at various operating speeds and cycle numbers.

- Speed has a significant effect on rutting depth. When increasing the wheel speed from 0.5 to $1.0 \mathrm{Km} / \mathrm{h}(100 \%)$, the rut depth decreases about $22 \%$ in the rubberized and $24 \%$ in the conventional asphalt mixtures.

- The number of cycles has a significant effect on the rutting depth. When the number of cycles increases from 7500 to 15000 , the rut depth increases by about $25 \%$ in rubberized and $30 \%$ in conventional asphalt mixtures.

\section{ACKNOWLEDGMENT}

Sincere thanks to the staff at the University of Baghdad, Department of Civil Engineering, College of Engineering, for their assistance in completing this research.

\section{REFERENCES}

[1] M. Saleh and M. Ghorban Ebrahimi, "Finite Element Modeling of Permanent Deformation in the Loaded Wheel Tracker Test," Transportation Research Record, vol. 2641, no. 1, pp. 94-102, Jan. 2017, https://doi.org/10.3141/2641-12.

[2] F. Alzaidy and A. H. K. Albayati, "A Comparison between Static and Repeated Load Test to Predict Asphalt Concrete Rut Depth," Engineering, Technology \& Applied Science Research, vol. 11, no. 4, pp. 7363-7369, Aug. 2021, https://doi.org/10.48084/etasr.4236.

[3] J. Wu, J. Liang, and S. Adhikari, "Dynamic response of concrete pavement structure with asphalt isolating layer under moving loads," Journal of Traffic and Transportation Engineering (English Edition), vol. 1, no. 6, pp. 439-447, Dec. 2014, https://doi.org/10.1016/S20957564(15)30294-4. 
[4] Harold L. Von Quintus, "Performance Prediction Models In the Superpace Mix Design System," Strategic Highway Research Program, Washington, D.C., USA, SHRP-A-699, Aug. 1994. Accessed: Oct. 30, 2021. [Online]. Available: https://trid.trb.org/view/406369.

[5] A. C. Collop, A. (Tom) Scarpas, C. Kasbergen, and A. de Bondt, "Development and Finite Element Implementation of Stress-Dependent Elastoviscoplastic Constitutive Model with Damage for Asphalt," Transportation Research Record, vol. 1832, no. 1, pp. 96-104, Jan. 2003, https://doi.org/10.3141/1832-12.

[6] J. Ji, L. Chen, Z. Suo, Y. Xu, and Y.-L. Han, "Effect of high temperature and heavy load on deformation resistance of DCLR modified asphalt mixture," Jiaotong Yunshu Gongcheng Xuebao/Journal of Traffic and Transportation Engineering, vol. 19, pp. 1-8, Feb. 2019.

[7] M. M. Pradhan, "Permanent deformation characteristics of asphaltaggregate mixtures using varied materials and molding procedures with Marshall method," Ph.D. dissertation, Montana State University, Bozeman, MT, USA, 1995

[8] E. G. Epifanio and L. Gan, "Validation of a Pavement Performance Model for Flexible Pavements Based on," M.S. thesis, Chalmers University of Technology, Gothenburg, Sweden, 2009.

[9] I. A. Mahmoud, "Performance Modification of Saudi Asphalt Binders Using SABIC Polymers," M.S. thesis, King Fahd University of Petroleum \& Minerals, Dhahran, Saudi Arabia, 2002.

[10] H. Ziari, A. Goli, and A. Amini, "Effect of Crumb Rubber Modifier on the Performance Properties of Rubberized Binders," Journal of Materials in Civil Engineering, vol. 28, no. 12, Dec. 2016, Art. no. 04016156, https://doi.org/10.1061/(ASCE)MT.1943-5533.0001661.

[11] A. Amini, H. Ziari, and A. Goli, "Investigating the performance of rubberised binders used in Iran based on multiple stress creep recovery and performance grading systems," Road Materials and Pavement Design, vol. 19, no. 4, pp. 803-818, May 2018, https://doi.org/ 10.1080/14680629.2016.1274676.

[12] K. Jadidi, M. Khalili, M. Karakouzian, and S. Amirkhanian, "Toughness, Tenacity and Maximum Initial Strength of Rubber Modified Asphalt Binders," Engineering, Technology \& Applied Science Research, vol. 9, no. 1, pp. 3765-3769, Feb. 2019, https://doi.org/10.48084/etasr.2526.

[13] M. Bekhiti, H. Trouzine, and A. Asroun, "Properties of Waste Tire Rubber Powder," Engineering, Technology \& Applied Science Research, vol. 4, no. 4, pp. 669-672, Aug. 2014, https://doi.org/10.48084/ etasr.439.

[14] M. Arabani, R. Jamshidi, and M. Sadeghnejad, "Using of 2D finite element modeling to predict the glasphalt mixture rutting behavior," Construction and Building Materials, vol. 68, pp. 183-191, Oct. 2014, https://doi.org/10.1016/j.conbuildmat.2014.06.057.

[15] J. Hua, "Finite element modeling and analysis of accelerated pavement testing devices and rutting phenomenon," Ph.D. dissertation, Purdue University, West Lafayette, IN, U.S., 2000.

[16] B. Bakhshi and M. Arabani, "Numerical Evaluation of Rutting in Rubberized Asphalt Mixture Using Finite Element Modeling Based on Experimental Viscoelastic Properties," Journal of Materials in Civil Engineering, vol. 30, no. 6, Jun. 2018, Art. no. 04018088, https://doi.org/10.1061/(ASCE)MT.1943-5533.0002116.

[17] T. D. White, J. E. Haddock, A. J. T. Hand, and H. Fang, "Contributions of Pavement Structural Layers to Rutting of Hot Mix Asphalt Pavements," Transportation Research Board - National Research Council, Washington, D.C., USA, 468, 2002. Accessed: Oct. 31, 2021. [Online]. Available: https://trid.trb.org/view/710690.

[18] "Abaqus 6.11 - Scripting User's Manual," Dassault Systèmes Simulia, 2011.

[19] F. Bai, X. Yang, and G. Zeng, "A stochastic viscoelastic-viscoplastic constitutive model and its application to crumb rubber modified asphalt mixtures," Materials \& Design, vol. 89, pp. 802-809, Jan. 2016, https://doi.org/10.1016/j.matdes.2015.10.040.

[20] Y. H. Huang, Pavement analysis and design. Englewood Cliffs, N.J., U.S.: Prentice-Hall, 1993. 